\title{
PELABELAN GRACEFUL GANJIL PADA GRAF DUPLIKASI DAN SPLIT BINTANG
}

\author{
J. A. Bantara1, I. W. Sudarsana ${ }^{2}$, dan S. Musdalifah ${ }^{3}$ \\ 1,2,3 Program Studi Matematika Jurusan Matematika FMIPA Universitas Tadulako \\ Jalan Sukarno-Hatta Km. 9 Palu 94118, Indonesia \\ 1jeinbantara31@yahoo.com, 2sudarsanaiwayan@yahoo.co.id, 3selvymusdalifah@yahoo.com
}

\section{ABSTRACT}

Graph $G$ is not an empty a finite of the objects that called point (vertex) with the couple was not that is the side (edge). The set point $G$ denoted by $V(G)$, while the set edge denoted by $E(G)$. Odd graceful labeling on graph $G$ with $q$ side is a function injective $f$ from $V(G) \rightarrow\{0,1,2, \ldots, 2 q-1\}$ so that induced function $f^{*} E(G) \rightarrow\{1,3,5, \ldots, 2 q-$ 1 ) such that $(x, y)$ in label with $|f(x)-f(y)|$ so label sides would be different. A graph $G$ that have an odd graceful labeling is called odd graceful graph. The result showed that duplicate star graph $D_{2}\left(K_{1, n}\right)$ for $n \geq 2$,and split star graph $\operatorname{spl}\left(K_{1, n}\right)$ for $n \geq 2$, for $n$ even satisfie odd graceful labeling.

Keywords : Duplicate Star Graph, Split Star Graph, Odd Graceful Labeling.

\section{ABSTRAK}

Secara umum graf $G$ adalah himpunan tak-kosong yang berhingga dari objek - objek yang disebut titik (vertex) bersama dengan himpunan pasangan tak-terurut yaitu sisi (edge). Himpunan titik $G$ dinotasikan dengan $V(G)$, sedangkan himpunan sisi dinotasikan dengan $E(G)$. Pelabelan Graceful Ganjil pada graph $G$ dengan $q$ sisi adalah fungsi injektif $f$ dari $V(G) \rightarrow\{0,1,2, \ldots, 2 q-1\}$ sehingga diinduksi fungsi $f^{*} E(G) \rightarrow\{1,3,5, \ldots, 2 q-1\}$ sedemikian hingga $(x, y)$ dilabeli dengan $|f(x)-f(y)|$ maka label sisinya akan berbeda. Sebuah graf $G$ yang mempunyai pelabelan graceful ganjil dinamakan graf graceful ganjil. Hasil penelitian menunjukkan bahwa graf duplikasi bintang $D_{2}\left(K_{1, n}\right)$ untuk $n \geq 2$, dan graf split bintang $\operatorname{spl}\left(K_{1, n}\right)$ untuk $n \geq 2$ untuk $n$ genap, adalah pelabelan graceful ganjil.

Kata kunci : : Graf Duplikasi Bintang, Graf Split Bintang, Pelabelan Graceful Ganjil. 


\section{PENDAHULUAN}

\subsection{Latar Belakang}

Matematika berasal dari bahasa Yunani yaitu mathema yang diartikan sebagai sains, ilmu pengetahuan, atau belajar, dan juga mathematikos adalah suka belajar. Matematika dalam bahasa Belanda disebut Wiskunde atau ilmu pasti, yang kesemuanya berkaitan dengan penalaran. Matematika dikenal sebagai Mother of Science, karena matematika merupakan salah satu cabang ilmu pengetahuan yang mempunyai kelebihan dibandingkan cabang - cabang ilmu lainnya. Selain itu matematika juga mempunyai banyak manfaat, karena banyak permasalahan dalam kehidupan yang dapat diselesaikan dengan menggunakan konsep - konsep matematika. Sebagian besar masyarakat menganggap matematika hanya merupakan ilmu menghitung bilangan-bilangan dengan menggunakan beberapa operasi dasar; tambah, kurang, kali dan bagi. Seiring perkembangan zaman, ilmu matematika berkembang dan hadir sebagai hal yang mendasar dan perlu dipelajari pada setiap disiplin keilmuan (Bambang Riadi, 2009). Gafur (2008) mengatakan bahwa ilmu pengetahuan dan teknologi tidak lepas dari peran serta ilmu matematika. Aplikasi ilmu matematika sangat banyak sekali dalam ilmu pengetahuan lain, salah satunya adalah teori graf. Teori graf adalah salah satu cabang matematika diskret yang penting dan banyak manfaatnya, antara lain dalam komunikasi, transportasi, sistem antrian, penjadwalan dan lain sebagainya.Secara umum graf $G$ adalah himpunan tak-kosong yang berhingga dari objek objek yang disebut titik (vertex) bersama dengan himpunan pasangan tak-terurut yaitu sisi (edge). Himpunan titik $G$ dinotasikan dengan $V(G)$, sedangkan himpunan sisi dinotasikan dengan $E(G)$. Menurut catatan sejarah (1736), masalah jembatan Konigsberg adalah masalah yang pertama kali menggunakan graf.Oleh karena itu, Euler (1707-1782) menjadi Bapak dari Teori Graf sebagaimana topologi ketika dia merumuskan mengenai masalah terkenal yang tak terpecahkan di atas. Peristiwa itulah yang menjadi tombak sejarah munculnya Teori Graf dan terus berkembang sampai sekarang karena kajiannya berhubungan dengan pemecahan masalah sehari - hari.

Pelabelan graceful adalah salah satu yang luas penggunaanya, terutama diaplikasikan dalam radar, jaringan komunikasi, desain circuit, teori coding, astronomi dan kristalografi. Studi tentang graf graceful dan metode pelabelan graceful diperkenalkan oleh Rosa. Selanjutnya pada tahun 1972 Golomb menamakannya pelabelan Graceful. Tahun 1991, Gnanajothi memperkenalkan pelabelan graceful ganjil yang merupakan pengembangan dari pelabelan graceful. Pelabelan graceful ganjil pada graf $G$ dengan $q$ sisi adalah pemetaan injektiff $: V(G) \rightarrow\{0,1,2, \ldots, 2 q-1\}$ sedemikianhingga setiap sisi $(x, y)$ dilabeli dengan $\mid f(x)-$ $f(y) \mid$ maka label sisinya adalah $E(G) \rightarrow\{1,3,5, \ldots, 2 q-1\}$. 
Pelabelan graceful adalah salah satu yang luas penggunaanya, terutama diaplikasikan dalam radar, jaringan komunikasi, desain circuit, teori coding, astronomi dan kristalografi. Studi tentang graf graceful dan metode pelabelan graceful diperkenalkan oleh Rosa. Selanjutnya pada tahun 1972 Golomb menamakannya pelabelan Graceful. Tahun 1991, Gnanajothi memperkenalkan pelabelan graceful ganjil yang merupakan pengembangan dari pelabelan graceful. Pelabelan graceful ganjil pada graf $G$ dengan $q$ sisi adalah pemetaan injektiff $: V(G) \rightarrow\{0,1,2, \ldots, 2 q-1\}$ sedemikianhingga setiap sisi $(x, y)$ dilabeli dengan $\mid f(x)-$ $f(y) \mid$ maka label sisinya adalah $E(G) \rightarrow\{1,3,5, \ldots, 2 q-1\}$.

Menurut Mahmoudzadeh (2010), nama pelabelan graceful dikemukakan oleh Solomon W. Golomb namun pelabelan awal kelas ini diberi nama pelabelan $\beta$ ( $\beta$ labelings) oleh Alex Rosa pada tahun 1967. Kemudian dari pelabelan graceful, berkembang lagi menjadi pelabelan graceful ganjil.

Kajian terdahulu mengenai pelabelan graceful ganjil telah dibahas pada jurnal yang berjudul pelabelan graceful dan graceful ganjil ke beberapa graf antara lain graf triangular snake (Vaidya dan Shah, 2013). Sedangkan untuk graf duplikasi dan split masih menjadi masalah terbuka. Berdasarkan hal tersebut penulis tertarik untuk meneliti pengembangan dari pelabelan graceful ganjil pada graf duplikasi bintang $D_{2}\left(K_{1, n}\right)$ dan graf split bintang $\operatorname{spl}\left(K_{1, n}\right)$.

\subsection{Batasan Masalah}

Pada penelitian ini, graf yang dikaji adalah graf sederhana yang terhubung dan berhingga.

\section{METODE PENELITIAN}

1. Memulai penelitian

2. Studi literatur

3. Menotasikan titik dan sisi pada graf duplikasi bintang dan split bintang

4. Memberikan label pada titik dan sisi dari graf duplikasi bintang dan split bintang

5. Menganalisa pola pelabelan titik pada graf duplikasi bintang dan graf split bintang

6. Mendapatkan pola label titik dan sisi Graceful ganjil pada graf duplikasi bintang $D_{2}\left(K_{1, n}\right)$ dan graf split bintang $\operatorname{Spl}\left(K_{1, n}\right)$

7. Mendapatkan hasil yaitu membuat teorema yang di lengkapi dengan bukti-buktinya.

8. Selesai. 


\section{HASIL DAN PEMBAHASAN}

Dalam bab ini akan dibahas mengenai pelabelan graceful ganjil pada graf duplikasi bintang dan split. Pemetaan yang digunakan untuk melabelkan titik dan sisi pada graf duplikasi dan split adalah pemetaan injektif yang didefinisikan dari $|f(x)-f(y)|$. Kemudian untuk menunjukkan apakah graf duplikasi dan split dapat dilabelkan dan memiliki fungsi pelabelan graceful ganjil, maka langkah - langkah yang akan dilakukan adalah menotasikan titik dan sisi, memberikan label titik dan sisi serta merumuskan pola untuk mendapatkan fungsi titik dan fungsi sisi pada masing - masing graf.

\subsection{Penotasian Titik dan Sisi Secara Umum pada Graf $D_{2}\left(K_{1, n}\right)$}

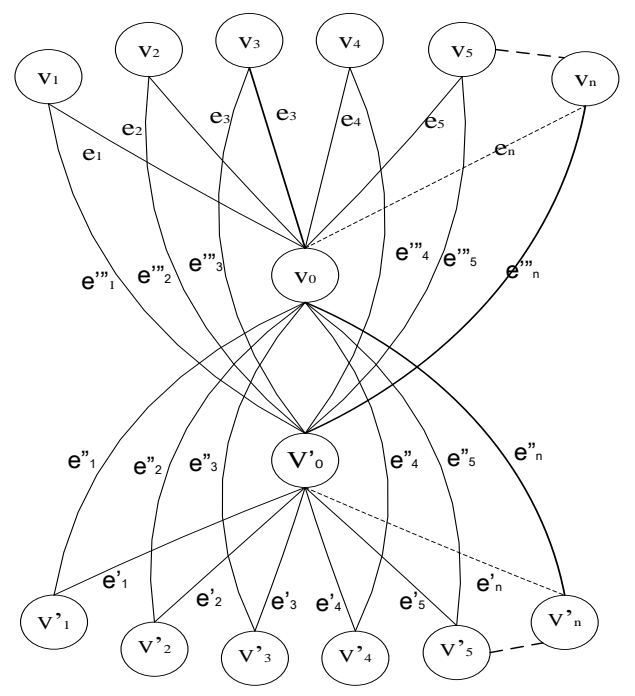

Gambar 1 : Penotasian titik dan sisi pada graf $D_{2}\left(K_{1, n}\right)$

\subsubsection{Pelabelan Graceful Ganjil untuk Graf $D_{2}\left(K_{1, n}\right)$}

Teorema $1: D_{2}\left(K_{1, n}\right)$, adalah graf graceful ganjil untuk $n \geq 2$.

Bukti :

Pandang graf $D_{2}\left(K_{1, n}\right)$ mempunyai banyaknya titik $p=n$ dan banyaknya sisi $q=n-1$. Berdasarkan penotasian titik dan sisi yang dinyatakan pada persamaan

$$
V\left(D_{2}\left(K_{1, n}\right)\right)=\left\{v_{0}, v_{0}^{\prime}, v_{i}, v_{i}^{\prime} 1 \leq i \leq n+1\right\}
$$

Notasi himpunan sisi pada graf $D_{2}\left(K_{1, n}\right)$ adalah :

$$
E\left(D_{2}\left(K_{1, n}\right)\right)=\left\{e_{i}, e_{i}^{\prime}, e_{i}^{\prime \prime}, e_{i}^{\prime \prime \prime} ; 1 \leq i \leq n-1\right\}
$$




\section{Dengan}

$$
\left.\begin{array}{r}
e_{i}=v_{i} v_{0} ; 1 \leq i \leq n \\
e_{i}^{\prime}=v_{i}^{\prime} v_{0}^{\prime} ; 1 \leq i \leq n \\
e_{i}^{\prime \prime}=v_{i} v_{0} ; 1 \leq i \leq n \\
e_{i}^{\prime \prime \prime}=v_{i}^{\prime} v_{0}^{\prime} ; 1 \leq i \leq n
\end{array}\right\}
$$

Didefinisikan fungsi injektif $f$ dari $V(G) \rightarrow\{0,1,2, \ldots, 2 q-1\}$ sebagai berikut.

$f\left(v_{0}\right)=0$

$f\left(v_{i}\right)=4(i-1)+3 ; 1 \leq i \leq n$

$f\left(v_{0}^{\prime}\right)=2$

$f\left(v_{i}\right)=4(n+1)-1 ; 1 \leq i \leq n$

Dengan demikian diperoleh label sisi sebagai berikut.

$f^{*}\left(e_{i}\right)=\left(f\left(v_{i}\right)-f\left(v_{0}\right)\right), \quad 1 \leq i \leq n$

$=((4(i-1)+3)-0)$,

$=(4(i-1)+3), \quad 1 \leq i \leq n$.

$f^{*}\left(e_{i}\right)=\left(f\left(v_{i}\right)-f\left(v_{0}^{\prime}\right)\right), \quad 1 \leq i \leq n$

$=(4(n+1)-1)-2)$,

$=4(n+1)-3, \quad 1 \leq i \leq n$.

$f^{*}\left(e_{i}^{\prime \prime}\right)=\left(f\left(v_{i}\right)-f\left(v_{0}\right)\right), \quad 1 \leq i \leq n$

$=((4(n+1)-1)-0)$,

$=((4(n+1)-1)), \quad 1 \leq i \leq n$.

$f^{*}\left(e_{i}^{\prime \prime}\right)=\left(f\left(v_{i}\right)-f\left(v_{0}^{\prime}\right)\right), \quad 1 \leq i \leq n$

$=(4(i-1)+3)-2)$,

$=4(i-1)+1, \quad 1 \leq i \leq n$

Berdasarkan fungsi pelabelan sisi pada graf $D_{2}\left(K_{1, n}\right)$ dapat didefinisikan himpunan sisi sebagai berikut :

$f^{*}(E)=\{(4(i-1)+3) ; 1 \leq i \leq n\} \cup\{(4(n+1)-3) ; 1 \leq i \leq n\}$

$\cup\{(4(n+1)-1) ; 1 \leq i \leq n\} \cup\{(4(i-1)+1) ; 1 \leq i \leq n\}$.

Pandang fungsi pelabelan sisi di atas, definisikan himpunan sisi sebagai berikut :

$$
\begin{gathered}
W=\left\{f^{*}\left(e_{i}\right)=f\left(v_{i}\right)-f\left(v_{0}\right) ; 1 \leq i \leq n\right\} \cup\left\{f^{*}\left(e_{i}\right)=f\left(v_{i}^{\prime}\right)-f\left(v_{0}^{\prime}\right) ; 1 \leq i \leq n\right\} \cup \\
\left\{f^{*}\left(e_{i}^{\prime}\right)=f\left(v_{i}^{\prime}\right)-f\left(v_{0}\right) ; 1 \leq i \leq n\right\} \cup\left\{f^{*}\left(e_{i}^{\prime \prime}\right)=f\left(v_{i}\right)-f\left(v_{0}^{\prime}\right) ; 1 \leq i \leq n\right\} \\
=\{4(i-1)+3 ; 1 \leq i \leq n\} \cup\{4(n+1)-3 ; 1 \leq i \leq n\} \cup \\
\{4(n+1)-1 ; 1 \leq i \leq n\} \cup\{4(i-1)+1 ; 1 \leq i \leq n\} \\
=\{3,7, \ldots, 4(i-1)+3\} \cup\{21,25, \ldots, 4(n+1)-3\} \cup\{1,5, \ldots, 4(n+1)-1\} \\
\quad \cup\{23,27, \ldots, 4(i-1)+1\} \\
=\{1,3,5, \ldots, 8 n-1\} .
\end{gathered}
$$


Dengan demikian, dapat dilihat bahwa semua anggota $W$ adalah ganjil, oleh karena itu, graf $D_{2}\left(K_{1, n}\right)$ mempunyai pelabelan graceful ganjil.

Contoh :

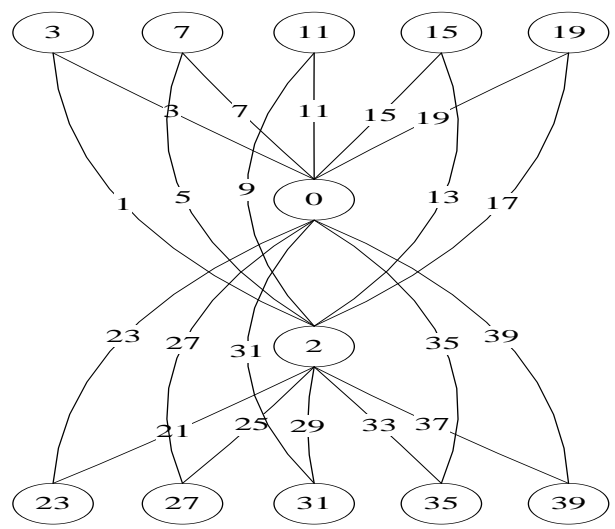

Gambar 2 : Pelabelan Graceful Ganjil pada graf $D_{2}\left(K_{1,5}\right)$

\subsection{Penotasian Titik dan Sisi Secara Umum pada Graf $\operatorname{Spl}\left(K_{1, n}\right)$}

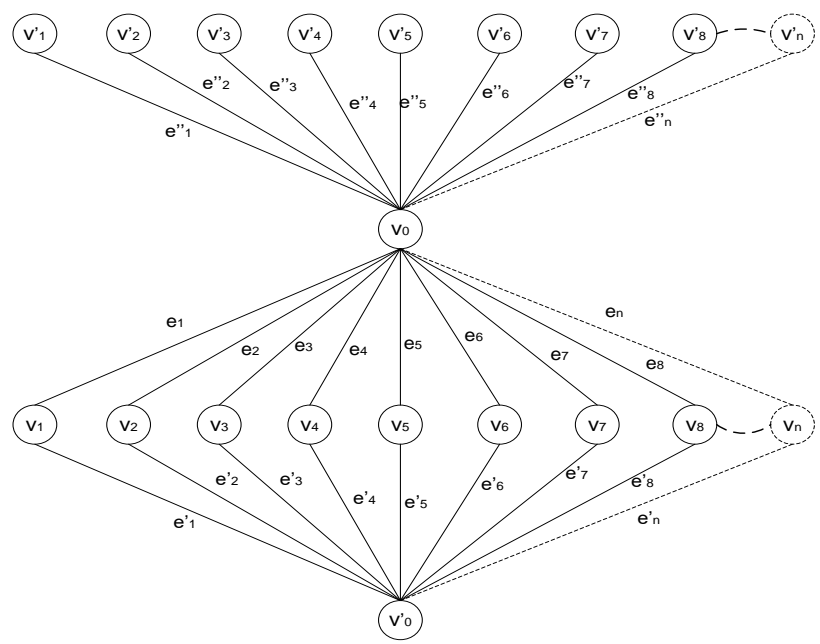

Gambar 3 : Penotasian titik dan sisi pada graf $\operatorname{Spl}\left(K_{1, n}\right)$

3.2.1. Pelabelan graceful ganjil untuk Graf $\operatorname{Spl}\left(K_{1, n}\right)$

Teorema $2: \operatorname{Spl}\left(K_{1, n}\right)$ adalah graf graceful ganjil untuk $\mathrm{n} \geq 2$.

Bukti :

Pandang graf $\operatorname{Spl}\left(K_{1, n}\right)$ mempunyai banyaknya titik $p=n$ dan banyaknya sisi $q=n-1$. Berdasarkan penotasian titik dan sisi yang dinyatakan pada persamaan 
$V\left(\operatorname{Spl}\left(K_{1, n}\right)\right)=\left\{v_{0}, v_{0}^{\prime}, v_{i}, v_{i}^{\prime} 1 \leq i \leq n+1\right\}$

Notasi himpunan sisi pada graf $\operatorname{Spl}\left(K_{1, n}\right)$ adalah :

$E\left(\operatorname{Spl}\left(K_{1, n}\right)\right)=\left\{e_{i}, e_{i}^{\prime}, e_{i}^{\prime \prime} ; 1 \leq i \leq n\right\}$.

\section{Dengan}

$$
\left.\begin{array}{l}
e_{i}=v_{i} v_{0} ; 1 \leq i \leq n \\
e_{i}^{\prime}=v_{i} v_{0}^{\prime} ; 1 \leq i \leq n \\
e_{i}^{\prime \prime}=v_{i}^{\prime} v_{0} ; 1 \leq i \leq n
\end{array}\right\}
$$

Didefinisikan fungsi injektif $f$ dari $V(G) \rightarrow\{0,1,2, \ldots, 2 q-1\}$ sebagai berikut.

$f\left(v_{0}\right)=0$

$f\left(v_{i}\right)=2(i-1)+1 ; 1 \leq i \leq n$

$f\left(v_{0}^{\prime}\right)=2$

$f\left(v_{i}\right)=4(i+2 n)-1 ; 1 \leq i \leq n$

Dengan demikian diperoleh label sisi sebagai berikut.

$f^{*}\left(e_{i}\right)=\left(f\left(v_{i}\right)-f\left(v_{0}\right)\right), \quad 1 \leq i \leq n-1$

$=((2(i-1)+1)-0)$,

$=2(i-1)+1, \quad 1 \leq i \leq n$.

$f^{*}\left(e_{i}\right)=\left(f\left(v_{i}\right)-f\left(v_{0}^{\prime}\right)\right), \quad 1 \leq i \leq n-1$

$=((2(i-1)+1)-2)$,

$=2(i-1)-1, \quad 1 \leq i \leq n-1$.

$f^{*}\left(e_{i}^{\prime}\right)=\left(f\left(v_{i}\right)-f\left(v_{0}\right)\right), \quad 1 \leq i \leq n-1$

$=((4(i+2 n)-1)-0)$,

$=(4(i+2 n)+1), \quad 1 \leq i \leq n-1$.

Berdasarkan fungsi pelabelan sisi pada graf $\operatorname{spl}\left(K_{1, n}\right)$ dapat didefinisikan himpunan sisi sebagai berikut :

$$
\begin{aligned}
f^{*}(E)=\{2(i-1) & +1 ; 1 \leq i \leq n-1\} \cup 2(i-1)-1 ; 1 \leq i \leq n-1\} \cup\{4(i+2 n)+1 ; 1 \\
\leq & i \leq n-1\} .
\end{aligned}
$$

Pandang fungsi pelabelan sisi di atas, definisikan himpunan sisi sebagai berikut :

$$
\begin{aligned}
& W=\left\{f^{*}\left(e_{i}\right)=f\left(v_{i}\right)-f\left(v_{0}\right) ; 1 \leq i \leq n-1\right\} \cup\left\{f^{*}\left(e_{i}\right)=f\left(v_{i}\right)-f\left(v_{0}^{\prime}\right) ; 1 \leq i \leq n-1\right\} \\
& \cup \\
& \left\{f^{*}\left(e_{i}^{\prime \prime}\right)=f\left(v_{i}^{\prime}\right)-f\left(v_{0}\right) ; 1 \leq i \leq n-1\right\} \\
& =\left\{4 i+2 n-1 ; \begin{array}{r}
\quad \leq i \leq n-1\} \cup\{4 i+2 n-3 ; 1 \leq i \leq n-1\} \cup\{2(i-1)+1 ; 1 \leq i \\
\quad \leq n-1\}
\end{array}\right. \\
& =\{11,15, \ldots, 2(i-1)+1\} \cup\{9,13, \ldots, 2(i-1)-1\} \cup\{1,3, \ldots, 4(i+2 n)+1\} \\
& =\{1,3,5, \ldots, 6 n-1\} .
\end{aligned}
$$

Dengan demikian, dapat dilihat bahwa semua anggota $W$ adalah ganjil, oleh karena itu, graf $\operatorname{spl}\left(K_{1, n}\right)$ mempunyai pelabelan graceful ganjil untuk $n$ genap. 
Contoh :

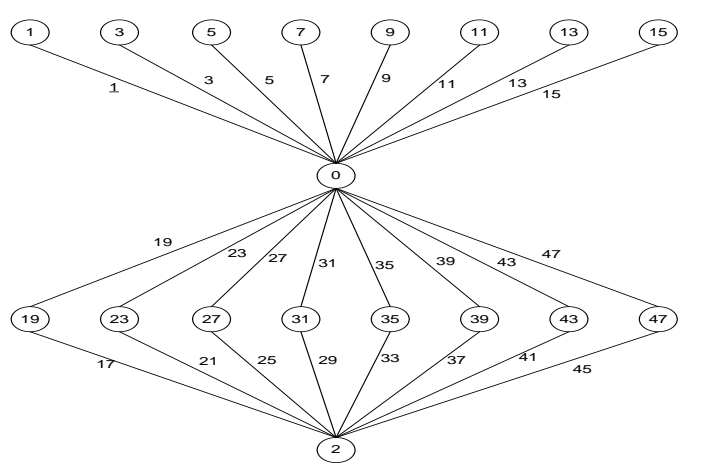

Gambar 4 : Pelabelan graceful ganjil pada $\operatorname{Spl}\left(K_{1,9}\right)$

\section{KESIMPULAN}

Berdasarkan hasil penelitian yang telah dilakukan, dapat disimpulkan bahwa :

1. Graf $D_{2}\left(K_{1, n}\right)$ untuk $n \geq 2$ adalah graf graceful ganjil.

2. Graf $\operatorname{Spl}\left(K_{1, n}\right)$ untuk $n \geq 2$, untuk $n$ genap adalah graf graceful ganjil. Sementara itu, untuk $n$ ganjil belum dapat di buktikan. Karena tidak memenuhi syarat dan definisi pelabelan graceful ganjil.

\section{DAFTAR PUSTAKA}

[1] Badr, E, M, dan Abdel-aal, E, M, Odd Gracseful Labeling For The Subdivison of Double Triangles Graphs, International Journal of Soft Computing, Mathematics and Control (IJSCMC), Vol 2, No 1, 2013.

[2] Vaidya, S.K., and Shah, N.H., Graceful and Odd Graceful Labeling of Some Graphs, 2013., International Journal of Mathematics and Soft Computing Vol. 3 , No. 1, 2013, $61-68$.

[3] F, Royle, Gordon, Counting Set Covers and Split Graph. Journal of Integer Sequences, 2000.

[4] Kotzig, A, and Rosa, A, Magic Valuations of Finite Graphs. Canadian Mathematical Bulletin, 1970, Vol.13, 451-461.

[5] Mahmoudzadeh, H, A Metaherurristic Approach to The Graceful Labeling Problem. International Journal of Applied Matheuristic Computing, Kourosh Eshghi, Sharif University of Technology, Iran 2010, Hal 42-56. 